\title{
Multi-objective Optimisation of Aircraft Departure Trajectories
}

DOI:

10.1016/j.ast.2018.05.032

Document Version

Accepted author manuscript

Link to publication record in Manchester Research Explorer

\section{Citation for published version (APA):}

Zhang, M., Filippone, A., \& Bojdo, N. (2018). Multi-objective Optimisation of Aircraft Departure Trajectories.

Aerospace Science and Technology, 79, 37-47. https://doi.org/10.1016/j.ast.2018.05.032

\section{Published in:}

Aerospace Science and Technology

\section{Citing this paper}

Please note that where the full-text provided on Manchester Research Explorer is the Author Accepted Manuscript or Proof version this may differ from the final Published version. If citing, it is advised that you check and use the publisher's definitive version.

\section{General rights}

Copyright and moral rights for the publications made accessible in the Research Explorer are retained by the authors and/or other copyright owners and it is a condition of accessing publications that users recognise and abide by the legal requirements associated with these rights.

\section{Takedown policy}

If you believe that this document breaches copyright please refer to the University of Manchester's Takedown Procedures [http://man.ac.uk/04Y6Bo] or contact uml.scholarlycommunications@manchester.ac.uk providing relevant details, so we can investigate your claim.

\section{OPEN ACCESS}




\title{
Multi-objective Optimisation of Aircraft Departure Trajectories
}

\author{
Mengying Zhang ${ }^{\mathrm{a}}$, Antonio Filippone ${ }^{\mathrm{a}, *}$, Nicholas Bojdo ${ }^{\mathrm{a}}$ \\ ${ }^{a}$ School of MACE, The University of Manchester, UK, M13 9PL.
}

\begin{abstract}
A multi-objective trajectory optimisation has been developed to minimise multiple environmental impacts (noise and exhaust emissions) from commercial airplanes. Three different non-gradient algorithms are used. First, a parameterization method is established for airplane departure trajectories, with path constraints considered where necessary. Second, a method to parameterize movement in the lateral plane based on a Bézier curve has been proposed to decrease the number of free parameters. The environmental impacts on target areas have been simulated by a comprehensive flight mechanics program. Finally, two posterior selection strategies based on preference function and monetisation approaches are used to evaluate the resulting Pareto solution set. A case study for a departure of an Airbus A320-211 with population distribution of residential communities around Manchester Airport (ICAO code: EGCC) is carried out with three different optimisers. We demonstrate that this simulation framework is able to solve trajectory optimisation problems with multiple simultaneous environmental objectives.
\end{abstract}

Keywords:

Aircraft Noise, Environmental Emissions, Trajectory Optimisation, Multi-Objective Optimisation

${ }^{*}$ Corresponding author

Email address: A.Filippone@manchester.ac.uk (Antonio Filippone) 


\section{Nomenclature}

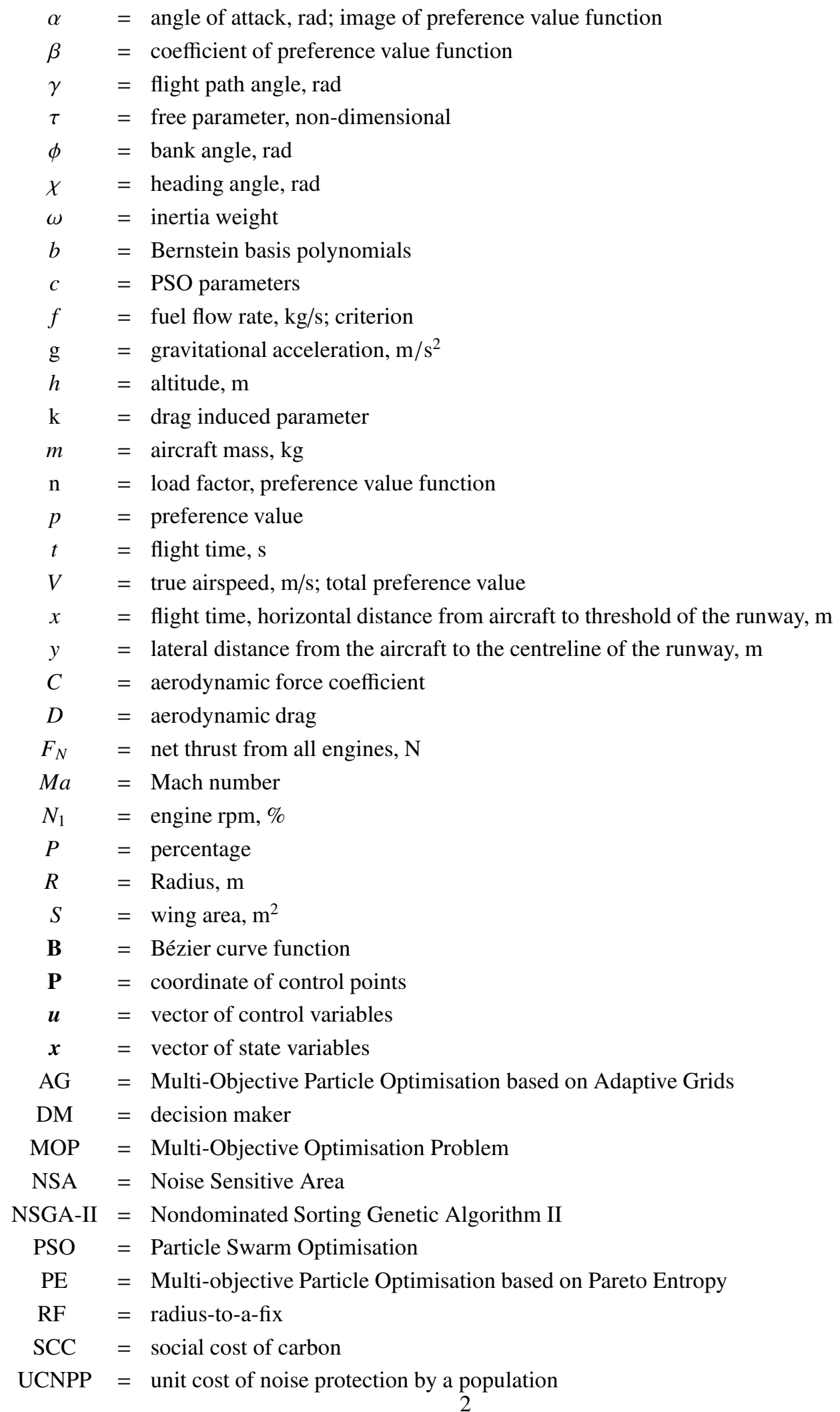




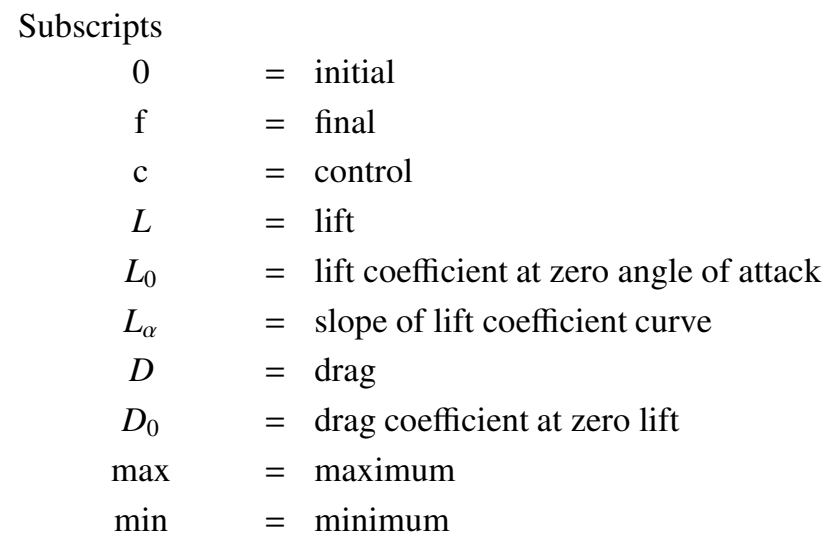

\section{Introduction}

Meeting community expectation in terms of sustainable development of commercial aviation remains a challenge, in spite of more stringent policies and regulations to control noise emission and exposure. The fact that the population within the $57 \mathrm{dBA}$ contour for the four largest airports in the UK has fallen by about $30 \%$ during the 14 years ending in 2011 [1,2] appears not to diminish the perception that aircraft noise is worsening [3]. The problem is not only how to guarantee a quieter, cleaner and more efficient flight, but how to compensate the additional environmental cost to support the development of the entire aviation industry, whilst meeting public concerns.

Although the potential for eliminating the environmental pressure by novel engines and aircraft configuration design seems promising, solutions that can be applied to the existing fleet and technology should not be underestimated. New air traffic management concepts have emerged in the United States under the name of NextGen [4], in Europe under the name of SESAR [5] and in Japan under the name of CARATS (Collaborative Actions for Renovation Air Traffic Systems) [6], with the aim of satisfying increasingly diverse requirements for airlines and passengers and to relieve the environment pressure of aviation.

Previous studies have shown that aircraft noise and exhaust emissions can be significantly reduced by trajectory optimisation [7, 8]. A trajectory optimisation tool named NOISHHH developed by Visser et al. [9, 10] integrated a noise model, a geographic information system and a dynamics trajectory optimisation algorithm with the collocation method; this method converts the continuous optimal control problem into a finite-dimensional nonlinear programming problem [11]. Similar algorithms have been implemented in the optimisation methodology developed by Hartjes et al.[12] to solve multi-event aircraft trajectories problems. A multi-criteria optimisation strategy with the lexicographic-egalitarian technique is implemented by Prats et al. [13, 14] to minimise the noise annoyance in Noise Sensitive Areas (NSA). Further studies showing a comparison between gradient-based methods was published by Khardi et al. [15], resulting in a preference towards the direct method.

Despite the effectiveness of the gradient- or derivative-based methods mentioned, difficulties arise when attempt is made to solve optimisation problems for discontinuous models. With the increasing complexity of current optimi- 
sation problems, there is no guarantee that optimisation problems can always be constructed with continuous models that can be differentiable. This shortcoming has led to the prosperity of several heuristic algorithms that are less computationally expensive, but do not need gradient information. This feature makes them more suitable and flexible for the optimisation problems described in this paper. A multi-objective mesh adaptive direct search method used by Torres et al. [16] aims to minimise noise and Nitrogen Oxides $\left(\mathrm{NO}_{\mathrm{x}}\right)$ emissions for departing aircraft. Yu et al. [17, 18] performed state parameterizations with Bernstein polynomials to discretise the noise impact optimisation for arrival trajectories with a genetic algorithm. Similarly, Hartjes and Visser [19] applied genetic algorithms to departure flight path planning for noise abatement and emission reduction. Ho-Huu et al. [20] explored evolutionary algorithms based on decomposition (MOEA/D) for noise abatement trajectories.

Thus, there is evidence that non-gradient algorithms are suitable for solving this category of optimisation problems. However, due to the large number of free parameters, there is a less optimistic view, because of the unfeasibly large number of function evaluations required. Moreover, with adding further environmental parameters or different noise attributes, an optimal solution cannot be selected from the solution set, unless further algorithms are introduced.

In this study, a trajectory optimisation framework based on non-gradient algorithms is developed. A new parameterisation method is implemented to discretise the flight dynamics equation on both vertical and lateral planes with a limited number of free parameters. Two posterior selection strategies based on aggregated preference function and monetisation approach respectively are applied to select the optimal solution within the Pareto solution set. The details of the problem formulation are explained in section 2, including the description of the multi-objective trajectory optimisation problems for environmental impacts minimization. The next two sections describe the proposed parameterization method with its implementation and the posterior selection strategies for the optimised solutions. Section 5 presents a numerical example of which results demonstrate the optimised departure trajectory from Manchester Airport. The aircraft flight mechanics, aerodynamics, propulsion and acoustic models used in this work are built based on the configuration of Airbus A320-211 with CFM56 engines.

\section{Problem Formulation}

\subsection{Dynamics equations}

A constrained trajectory optimisation problem is constructed with aircraft flight dynamics models, constraints of air traffic safety issues and cost functions of distinctive objectives. For the present scope, the aircraft is modelled as a rigid body with varying mass, aerodynamic, propulsive and gravitational forces. Some assumptions are made to simplify the problem: (1) flat and non-rotational Earth; (2) all forces acting on the aircraft through its centre of gravity; (3) zero angle between the engine thrust and the longitudinal axis of the aircraft; (4) small angle of attack $\alpha$. Thus, a 3 degrees-of-freedom flight dynamics model with a set of differential algebraic equations associated with a variable mass can be simplified as: 


$$
\left\{\begin{array}{l}
\dot{V}=\frac{F_{N}-m g \sin \gamma-D}{m} \\
\dot{\gamma}=\frac{L \cos \phi-m g \cos \gamma}{m V} \\
\dot{\chi}=\frac{L \sin \phi}{m V \cos \gamma} \\
\dot{x}=V \cos \gamma \sin \chi \\
\dot{y}=V \cos \gamma \cos \chi \\
\dot{h}=V \sin \gamma \\
\dot{m}=-f
\end{array}\right.
$$

where the state variables consist of true airspeed $V$, flight path angle $\gamma$, heading angle $\chi$, bank angle $\phi$, and three dimensional location parameters of the aircraft: $x, y, h$. The net thrust $F_{N}$, the angle of attack $\alpha$ to define aerodynamic forces, and the bank angle $\phi$ are the control variables. Other variables include the aerodynamics lift $L$, $\operatorname{drag} D$ and fuel flow rate $f$. To define the net thrust and the fuel flow rate, selected models based on FLIGHT [21] are introduced as:

$$
\begin{gathered}
F_{N}=F_{N}\left(h, M a, N_{1}\right) \\
f=f\left(h, M a, N_{1}\right)
\end{gathered}
$$

where $M a$ is the Mach number, $N_{1}$ is the engine rpm with value range [70\%,103\%] for the departure phase. Similarly, the calculation of the aerodynamics coefficients $C_{L}$ and $C_{D}$ is achieved based on current flight state variables, the configuration of Airbus A320-211 and custom-defined atmosphere parameters.

\subsection{Cost function}

Different attributes of the trajectory such as flight duration, fuel burnt, noise and exhaust emissions can be set as the optimisation objectives. The noise indices, including effective perceived noise level (EPNL), sound exposure level (SEL), equivalent noise level ( $\mathrm{L}_{\mathrm{AeqT}}$ ), maximum sound pressure level ( $\mathrm{SPL}_{\max }$ ), maximum A-weighting sound level $\left(\mathrm{L}_{\mathrm{Amax}}\right)$ and so on, can be obtained from the aircraft performance software FLIGHT [21]. Engine exhaust emissions can be calculated, such as carbon dioxide $\left(\mathrm{CO}_{2}\right)$, monoxide $(\mathrm{CO})$, nitrogen oxides $\left(\mathrm{NO}_{\mathrm{x}}\right)$ and other pollutants. Inputs required include trajectory data, as well as the engine performance data.

\subsection{Constraints}

Constraints that comply with the safety requirements are needed, as well as constraints normally required by air traffic control. First, there is neither descent nor deceleration during the departure: 


$$
\begin{gathered}
\gamma \geq 0^{\circ} \\
\dot{V} \geq 0 \mathrm{kt} / \mathrm{s}
\end{gathered}
$$

Second, path constraints regarding to safety and air traffic management issues for velocity and altitude are:

$$
\begin{aligned}
& V_{\text {stall }}<V \leq 250 \mathrm{kt} \\
& h_{0}<h \leq 10,000 \mathrm{ft}
\end{aligned}
$$

Third, the bank angle should be constrained:

$$
|\phi| \leq|\phi|_{\max }
$$

where $|\phi|_{\max }$ is derived in the following section. To define the initial and final condition, the following boundary constraints are given:

$$
\begin{gathered}
h\left(t_{0}\right)=h_{0}, \quad x\left(t_{0}\right)=x_{0}, \quad y\left(t_{0}\right)=y_{0} \\
h\left(t_{f}\right) \leq h_{\max }, \quad x\left(t_{f}\right)=x_{f}, \quad y\left(t_{f}\right)=y_{f}
\end{gathered}
$$

where $\left(x_{f}, y_{f}\right)$ is chosen from the coordinates of the way-points where the aircraft leave the controlled airspace.

\section{Segmentation and Parameterization}

\subsection{Decoupling of the Dynamics Equations}

This section introduces the method implemented to discretise the trajectory. Some assumptions are introduced to decouple the three dimensional model on the two motion planes.

First, the force normal to the flight path in the vertical plane is assumed to be in equilibrium, which leads to $\dot{\gamma}=0$ in every time step. Therefore, the equation to obtain the lift coefficient is given as:

$$
C_{L}=C_{L 0}+C_{L \alpha}(h, V) \alpha=\frac{2 m g \cos \gamma}{\rho V^{2} S \cos \phi}
$$

where $\rho$ is the atmospheric density, $S$ is the reference area. Then with a parabolic drag polar the drag force is derived:

$$
D=\frac{1}{2} \rho V^{2} S\left(C_{D 0}(h, V)+k(h, V) C_{L}^{2}\right)
$$




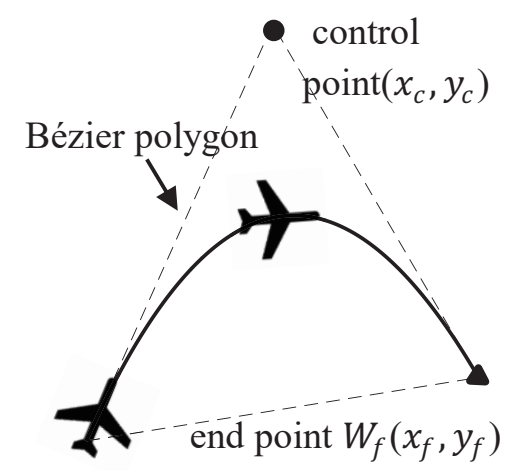

Figure 1: Bézier curve within the Bézier polygon.

where $C_{L 0}, C_{L \alpha}, C_{D 0}$ and $k$ are the aerodynamic coefficients. With Eq.11, the angle of attack $\alpha$ can be explicitly expressed by the state variables, including the unknown variable $\phi$. Then the flight path angle $\gamma$ becomes a the new control variable, together with the other two controls, the engine rpm $N_{1}$ and the bank angle $\phi$ to form the new control vector $\boldsymbol{u}=\left[N_{1}, \gamma, \phi\right]^{T}$. Thus, the motion described in Eq.1 can be decoupled in the horizontal plane and vertical plane respectively as:

$$
\text { Horizontal: }\left\{\begin{array} { l } 
{ \dot { x } = g \operatorname { t a n } \phi / V } \\
{ \dot { x } = V \operatorname { c o s } \gamma \operatorname { s i n } \chi } \\
{ \dot { y } = V \operatorname { c o s } \gamma \operatorname { c o s } \chi }
\end{array} \quad \text { Vertical: } \left\{\begin{array}{l}
\dot{V}=\left(F_{N}-m g \sin \gamma-D\right) / m \\
\dot{h}=V \sin \gamma \\
\dot{m}=-f
\end{array}\right.\right.
$$

\subsection{Horizontal plane: Previous parameterization and new Bézier curve}

Among the horizontal track parameterization methods, way-points are usually used to define the departure routes. The lateral tracks can be expressed by a series of way-points that construct the flight path between two desired positions. Two types of legs — track-to-a-fix (TF) leg and radius-to-a-fix (RF) legs — are preferred, which means the lateral trajectory is built with straight legs and constant radius turns [19, 22, 23]. Aside from way-points, trajectory models defined by spline interpolation have also been developed [24], including multi-event simultaneous routes optimisation using rational Bézier curves [25]. Conventionally, the way point method is adopted for its easy implementation of the constraints from existing operational requirements and air traffic guidance, while the second category might put more pressure on the situational awareness of the pilots. However, with the development of the technology of today's navigation and guidance, a far more complex situation could be handled with the increased airspace complexity caused by optimised free flight routes. In this paper, a parameterization method using Bézier approximation curve is imposed to obtain the horizontal track with the potential of reducing the dimensions of the search space.

A Bézier curve is defined by a set of control points $\mathbf{P}_{0}\left(x_{0}, y_{0}\right)$ to $\mathbf{P}_{n}\left(x_{n}, y_{n}\right)$, where $n$ is the order of the curve. There are two properties of the Bézier curve which make it suitable for the ground track construction. First, the section formed by connecting the first and the second control points is tangent to the curve at the first control point, and the 
section between the last and the penultimate control points is tangent to the curve at the last Bézier point. This feature allows users to control the tangential direction of the curve more easily by directly controlling the locations of the second and penultimate Bézier points. Moreover, since the two end-points are points of tangency of the first and last sections of the Bézier polygon, the curve can be split into two Bézier curves at any point and to be easily connected with another Bézier spline at any end point; this is suitable for piecewise ground path planning. Second, the convexhull of the Bézier polygon composed of control points would wrap around the Bézier curve (seen in Figure 1) . Given the population distribution around the airport, it is possible to approximate the flight corridor with the convex hull of the Bézier polygons within which the ground track would steer clear of the NSA. The curve is defined by:

$$
\mathbf{B}(\tau)=\sum_{i=0}^{n} b_{i, n}(\tau) \mathbf{P}_{i}, \quad \tau \in[0,1], i=0, \ldots, n
$$

where the polynomials

$$
b_{i, n}(\tau)=\left(\begin{array}{l}
n \\
i
\end{array}\right) \tau^{i}(1-\tau)^{n-i}, \quad i=0, \ldots, n
$$

are known as Bernstein basis polynomials of degree $n . \mathbf{P}_{i}$ are the coordinates of the control points and $\left(\begin{array}{l}n \\ i\end{array}\right)=\frac{n !}{i !(n-i) !}$ is the Binomial coefficient. The radius of curvature $R(\tau)$ on the curve is:

$$
R(\tau)=\frac{\left(x^{\prime 2}(\tau)+y^{\prime 2}(\tau)\right)^{3 / 2}}{\left|x^{\prime}(\tau) y^{\prime \prime}(\tau)-x^{\prime \prime}(\tau) y^{\prime}(\tau)\right|}
$$

The control variable bank angle $\phi$ can be derived as:

$$
|\phi|=\left|\tan ^{-1}\left(\frac{V^{2}}{g R(\tau)}\right)\right|
$$

where the radius $R$ can also be expressed as a function of speed $V$ and load factor $n$

$$
R=\frac{V^{2}}{g \tan \phi}=\frac{V^{2}}{g \sqrt{n^{2}-1}}
$$

$n=\frac{L}{m g}$ is the load factor in steady level turns. Then the bank angle is constrained as $|\phi| \leq|\phi|\left(n_{\max }\right)=\tan ^{-1} \sqrt{n_{\max }^{2}-1}$, $n_{\max }=1.10$. Note that the positive sign of the bank angle represents turning right; the negative indicates turning left; this direction can be determined by the analysis of the direction vectors change along the curve defined in Eq.14. Therefore, the control variable $\phi$ is explicitly controlled by the coordinates of the control points $\mathbf{P}_{i}$.

\subsection{Vertical Segmentation}

A segmented departure consists of climb and acceleration segments. In Figure 2 is one possible case with example parameter values. According to this flight sequence, two accelerations (i.e. AB and CD) and two constant-speed climbs (i.e. BC and DE) are taken into account. Focus will be on the parameters that describe the climb profile and their effect on the noise perceived at the NSA. Detailed explanation of the parameterization has been published in 


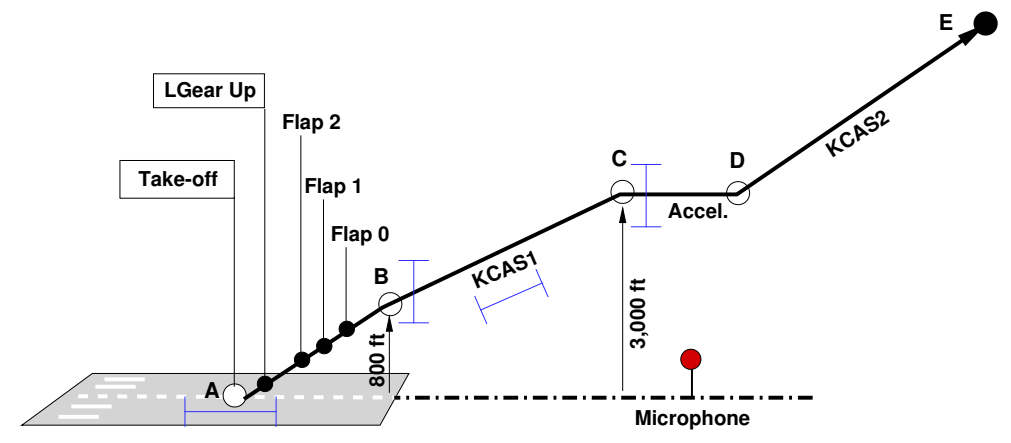

Figure 2: Take-off and climb-out trajectory, with key steps [27].

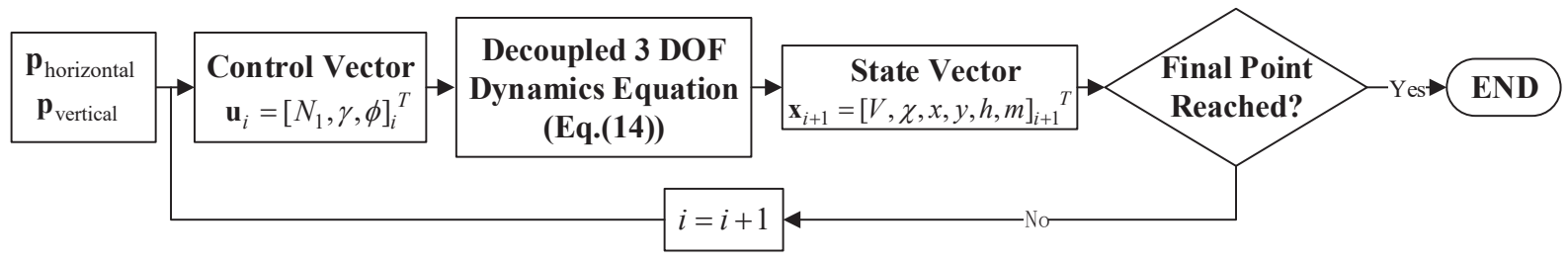

Figure 3: Computational procedure for a 3D flight dynamics model.

Ref. [26]. A description of each segment with the vertical free parameters is given in Table 2.

Table 2: Description of each segment.

\begin{tabular}{ccc}
\hline Segment & Description & Free Parameters \\
\hline $\mathrm{AB}$ & full trust acceleration while climbing & $\gamma_{A}, V_{B}, h_{B}$ \\
$\mathrm{BC}$ & constant climb & $\gamma_{B}$ \\
$\mathrm{CD}$ & level acceleration & $V_{D}, N_{1 C D}$ \\
$\mathrm{DE}$ & climbing/level flight & $\gamma_{C D}$ \\
\hline
\end{tabular}

In summary, the 3D departure trajectory can be parameterised through two sets of free parameters: horizontal free parameters $\mathbf{P}_{\text {horizontal }}$ to define the ground track and the vertical free parameters $\mathbf{P}_{\text {vertical }}$. Specifically, the parameter vector $\mathbf{P}_{\text {horizontal }}$ includes the coordinates of the control points $\mathbf{P}_{i}$ which can be derived from the control variable $\phi$, and the parameter vector $\mathbf{P}_{\text {vertical }}=\left[\gamma_{A}, V_{B}, h_{B}, \gamma_{B}, V_{D}, N_{1 C D}, \gamma_{D}\right]^{T}$ shown in Table 2 for segmented movement of the aircraft in the vertical plane. Therefore, the control vector $\boldsymbol{u}=\left[N_{1}, \gamma, \phi\right]^{T}$ can be fully discretized by $\mathbf{P}_{\text {horizontal }}$ and $\mathbf{P}_{\text {vertical }}$ which are later free parameters defined in the optimisation problem. Figure 3 displays the computational flow of solving the 3D flight dynamics model. 


\section{Function Optimisers}

Particle Swarm Optimisation (PSO) [28] has been widely used in optimisation problems due to its considerable performance in convergence speed. Revisions to extend the application of PSO from single objective optimisation to multi-objective optimisation have been developed, including strategies to determine the global and local optimal solution to lead the swarm, approaches to maintain the external archive to store, select and update current nondominated solutions, and methods to achieve a balance between exploration and exploitation [29]. Several multiobjective PSO models have been proposed; these include: weighted objective functions aggregated approaches [30], lexicographic ordering approaches based on the importance of the objectives [31], Pareto based approaches using the concept of Pareto dominance [32-35] to select leaders, and combined approaches.

Two Pareto based approaches are used in the following sections. One is the Adaptive Grid (AG) multi-objective PSO, one of the most classic Pareto-based multi-objective PSO. This model applies adaptive grids and mutation operator to updates external archive and determine global best [36]. The other is the Pareto Entropy (PE) multi-objective PSO, designed to adjust towards exploration and exploitation according to the feedback from the current evolutionary environment. Based on the parallel cell coordinate system and information entropy of the current Pareto optimal solutions, the latter algorithm was proposed to evaluate the diversity of the swarm and its evolutionary environment. For more details, see Ref. [37-39].

\section{Posterior Selection Strategy}

Instead of a single optimal solution, the result of Multi-Objective Optimisation Problem (MOP) is a set of Pareto optimal solutions. After obtaining the optimised solution set, it is not easy to define the criterion to select the best solution. The problem becomes more complex when multiple optimisers are used. In order to evaluate optimised solutions in intuitive and understandable methods, two posteriori selection strategies are introduced. The aggregated preference value function is built on the theory of physical programming [40] using the decision maker preferences. The other strategy is established by monetising a range of objectives (e.g. fuel, noise level and pollutant emissions), which depends more on the environmental policies and their damage costs. Note that if more than one optimiser is used, the solution set is obtained as union of the results achieved from each of the optimisers.

\subsection{Preference value function}

A method to evaluate the various departure procedures using the decision maker's (DM) preferences is introduced in this section. First, the preference type of different objectives is defined. Subsequently, essential knowledge and concerns from the DM are translated into preference functions with separate ranges to identify the preference levels. Finally, an aggregated preference function is built to generate a single metric for evaluation. As a result, the optimal solution can be selected by comparing these preference values from the solution set. In this paper, all the 
concerned objectives can be categorized into one classical type; smaller is better, according to the theory of physical programming [40].

Without loss of generality, for each criterion, there are $N$ ranges to express each level of desirability towards the $M$ criteria. Numerical values of the $i^{\text {th }}$ criterion $f_{i}(x)$ at the boundaries of these ranges are given as $f_{i}^{k}(i=1, \ldots, M ; k=$ $0,1, \ldots, N)$. The preference values are then ranked by their values in an ascending order, which means that the first has a highest desirability but with the smallest numerical value and the last is assigned the lowest desirability but with the largest numerical value. Usually the values to characterize the preferences mainly depend on the expertise of the DM. A generic example of 5 desirability levels is described in Table 3.

\begin{tabular}{ccc}
\multicolumn{3}{l}{ Table 3: Preferences order and the attribution with $N=5$} \\
level & Description & Value range \\
\hline A & Highly desirable & $f_{i}^{0}<f_{i} \leq f_{i}^{1}$ \\
B & Desirable & $f_{i}^{1}<f_{i} \leq f_{i}^{2}$ \\
C & Tolerable & $f_{i}^{2}<f_{i} \leq f_{i}^{3}$ \\
D & Undesirable & $f_{i}^{3}<f_{i} \leq f_{i}^{4}$ \\
E & Highly undesirable & $f_{i}^{4}<f_{i} \leq f_{i}^{5}$ \\
\hline
\end{tabular}

In order to weigh the different criteria with a common metric, the same set of images $\alpha_{k}$, defining the preference value at the boundary of each preference range, is adopted to construct the preference function. The images $\alpha_{k}$ at the boundaries $f_{i}^{k}$ are calculated as:

$$
\alpha_{k}= \begin{cases}0, & \text { if } k=0 \\ \alpha_{\text {ini }} M^{k-1}, & \text { if } 1 \leq k \leq N\end{cases}
$$

The values of $\alpha_{k}$ are dimensionless and are made of $\alpha_{\text {ini }}$ and the number of objectives $M$. The variable $\alpha_{\text {ini }}$ is set to be the same for all the objectives, and will be used to develop the preference functions with a piecewise exponential function [41].

For the general $k^{\text {th }}$ range, $f_{i}^{k-1}<f_{i} \leq f_{i}^{k}$, the preference function with order $n$ is defined as:

$$
p_{k}(x)=\alpha_{k-1}+\beta_{k}\left|1-\exp \left(-n \frac{f_{i}(x)-f_{i}^{k-1}}{f_{i}^{k}-f_{i}^{k-1}}\right)\right|
$$

Note that $n$ is a user-defined parameter which the piecewise exponential function is not sensitive to in the solution obtained at the posterior selection process. Since $p_{k}=\alpha_{k}$ at the boundary $f_{i}^{k}$, then the coefficient $\beta_{k}$ and preference value function of this range can be derived as:

$$
\begin{gathered}
\beta_{k}=\frac{\alpha_{k}-\alpha_{k-1}}{|1-\exp (-n)|} \\
p_{k}(x)=\alpha_{k-1}+\frac{\alpha_{k}-\alpha_{k-1}}{|1-\exp (-n)|}\left|1-\exp \left(-n \frac{f_{i}(x)-f_{i}^{k-1}}{f_{i}^{k}-f_{i}^{k-1}}\right)\right|
\end{gathered}
$$


Therefore, the preference function for the $i^{\text {th }}$ criterion can be expressed as:

$$
n_{i}^{1}(x)= \begin{cases}0, & f_{i}(x)<f_{i}^{0} \\ p_{k}(x), & f_{i}^{k-1} \leq f_{i}(x) \leq f_{i}^{k} \\ p_{N}(x), & f_{i}(x)>f_{i}^{N}\end{cases}
$$

where $1 \leq k \leq N$ and $p_{N}(x)=\alpha_{N}$. Finally, the decision-making process is to find the solution with the minimum $V(x)$ :

$$
\min _{x} V(x)=\sum_{i=1}^{M} n_{i}(x)
$$

\subsection{Monetisation Method}

An alternative method to measure the impact of noise and emissions is to value the economic expenditure to weigh them with the same metric. This method is called monetisation. It might not be appropriate to integrate attributes in the phase of optimisation, but it would be an objective method to assess solutions obtained in the posterior phase.

\section{(1) Cost of Aircraft Noise}

One way to monetise the cost of aircraft noise is to quantify the noise impacts based on the potential harm exerted on the exposed population. Among all the local concerns of the residential communities, annoyance, sleep disturbance, and awakenings are crucial from both physical and psychological aspects. The American National Standard Institute (ANSI) has identified one method that predicts the probability of an individual noise event awakening a person as a result of the SEL alone [42].

$$
P_{\text {awakening, }, \mathrm{k}}=\frac{1}{1+e^{-\left(-6.8884+0.04444 \mathrm{SEL}_{\text {indoor }}\right)}}
$$

where $\mathrm{SEL}_{\text {indoor }}=\mathrm{SEL}_{\text {outdoor }}-20.5 \mathrm{~dB}$.

However, monetising the effect of awakening is not easy. WHO has given disability weights to noise-induced annoyance, sleep disturbance and hypertension, but excluded awakening [43]. By using the value of the unit cost of noise protection for a population (UCNPP) [44], which is widely-used for noise problems, the potential cost caused by aviation noise can be monetised. Then the total damage cost can be expressed as:

$$
\text { Cost of awakening }=\sum \mathrm{UCNPP}_{\mathrm{k}} \cdot P_{\text {awakening,k }} \cdot \text { population }_{\mathrm{k}}
$$

where $P_{\text {awakening,k }}$ is the probability of awakening of people living in the $k^{\text {th }}$ noise sensitive zone enclosing a population of size population ${ }_{k}$. UCNPP is assigned the average total costs per person affected by noise prior to the implementation of noise reduction measures, which was discussed in the evaluation of Directive 2002/49/EC (the Environmental Noise Directive) [45]. The value of the case in Stuttgart Airport, which is $€ 5.66$ ( $£ 4.39$ ) per person, is set as the reference value of airports with annual operations ranging from 100,000 to 200,000.

(2) Cost of Exhaust Emissions 
A method to evaluate nitrogen oxides through the impact pathway and to estimate the damage cost as the discount in life years was provide by the UK Department of Environment, Food and Rural Affairs [46]. Due to the limitation of data, the $\mathrm{NO}_{\mathrm{x}}$ damage cost for average transport is used as the cost of $\mathrm{NO}_{\mathrm{x}}$ from aircraft flight operations, which is $£ 25,252$ per tonne at 2015 prices.

As for the cost of carbon dioxide emission, it is complex to give a price because this factor has dynamic long-term impacts on global environment. Carbon price, including the UK short-term traded carbon price, which is $£ 4.13$ at 2017 prices [47], is more applicable for Government investment and financial estimates rather than evaluating the damage cost of one single flight event. In another aspect, the Social Cost of Carbon (SCC) reflects the economic cost of climate change caused by one additional tonne of carbon dioxide emitted, which is more closely linked to the effects on human health, including lifetime curtailment [48]. A study from Miyoshi applied this concept to evaluate the $\mathrm{CO}_{2}$ damage cost produced by passengers on airport surface access in the case of Manchester Airport [49]. Recently, Nordhaus valued US SCC with an estimate of \$31 per ton in 2010 USD [50]. This value is therefore employed as the reference of $\mathrm{CO}_{2}$ damage cost in this study. Table 4 provides the damage costs of $\mathrm{NO}_{\mathrm{x}}$ and $\mathrm{CO}_{2}$ with currency converted into 2015 GBP. Thus, the posterior selection is to choose the minimum economic costs of obtained optimised solutions, which is given in Eq. 27:

$$
\text { min total cost }=\mathrm{UCNPP} \cdot \text { population }+\mathrm{UDC}_{\mathrm{NO}_{\mathrm{x}}} \cdot \mathrm{NO}_{\mathrm{x}}+\mathrm{UDC}_{\mathrm{CO}_{2}} \cdot \mathrm{CO}_{2}+\mathrm{UC}_{\text {fuel }} \cdot \text { fuel }
$$

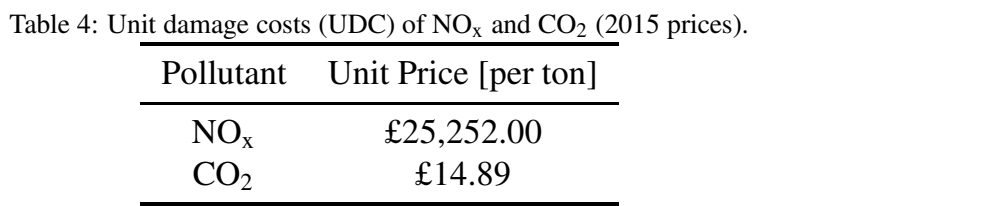

\section{Case Study}

To demonstrate the capability of the method proposed, we consider an Airbus 320-211 aircraft on a westbound departure from Manchester airport. Since there is a residential community near the end of runway 23R/05L in Knutsford, a UK gridded population based on the 2011 Census and the 2007 Land Cover Map [51] is introduced to estimate the exposure impacts by the aviation activities. The gridded population data based on the British National Grid (OSGB36 datum) has a $1 \mathrm{~km}$ by $1 \mathrm{~km}$ spatial resolution for each square cell. To simplify the problem, it is assumed that all the population enclosed in the grid cell are gathered in the geometric centre of it, so the noise impact on that grid cell will be estimated using the noise level (expressed in terms of SEL) received at that single point. The simplification is a compromise between accuracy and computational cost. Note that regular shapes of the grid cells can be altered (e.g. triangular cells, rectangular cells and hexagonal cells) [18], but here only the squares are utilised. 


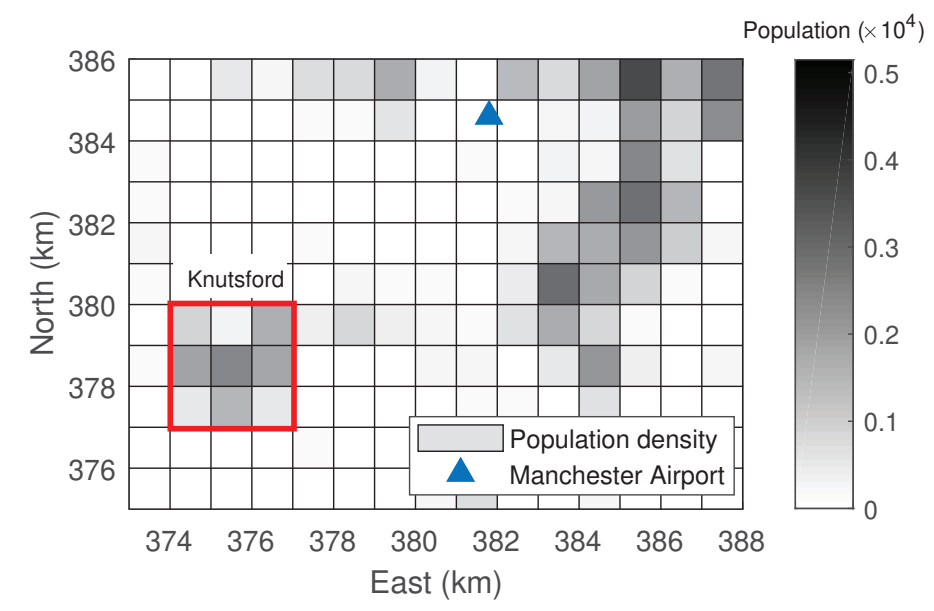

Figure 4: Population distribution in Knutsford and around Manchester Airport (OSGB36).

A noise-sensitive region of $3 \mathrm{~km}$ by $3 \mathrm{~km}$ in the town of Knutsford (coordinates: $53.30329^{\circ} \mathrm{N}, 2.37316^{\circ} \mathrm{W}$ ) with a population grid cell size of $1 \mathrm{~km}$ by $1 \mathrm{~km}$ is used for the analysis on departure operation. The population distribution around this region and Manchester airport is shown in Figure 4 with colour shades differentiated to indicate the density of the residents within the noise-sensitive region circled with a red rectangle.

The departure trajectory is optimised for noise minimization on Knutsford and carbon dioxide emissions:

$$
\min J_{1}=\mathrm{EPNL}, \quad J_{2}=\mathrm{CO}_{2}
$$

Note that $J_{1}$ is the EPNL measured at the centre of the cell of Knutsford. The noise level (i.e.SEL) received at the nine grid cells are used to calculate the cost of awakening in the process of posterior selection.

With the original coordinate located in the Runway end 23R, the aircraft departures with initial condition at $x_{0}=-916.71 \mathrm{~m}, y_{0}=-399.55 \mathrm{~m}, h_{0}=73 \mathrm{~m}, V_{0}=75 \mathrm{~m} / \mathrm{s}$. The end point $x_{f}=-18,119.20 \mathrm{~m}, y_{f}=-16,708.69 \mathrm{~m}$, is defined with the reference of an existing instrumental departure routing SANBA IRIY Noise Preferential Routing. Based on the method proposed in section 3.2, the lateral track to be optimised is segmented into the initial straight leg and the following Bézier curve segment with one free control point $\left(x_{c}, y_{c}\right)$. Note that the flight path angle $\gamma_{D E}$ along the vertical profile DE is given a reference value $2.8^{\circ}$ from the existing routing, and a fixed control point is added to ensure that the final heading of aircraft is $155^{\circ}$, which heads to SANBA at EGCC. The 3D trajectory is therefore fully described by 8 free parameters, and the original optimal control problem is discretised into a parameter optimisation problem. Table 5 gives the settings of the free parameters. The path constraints discussed in section 2.3 are added by applying penalty to the cost function.

Optimisers used in this study include GA [52] and multi-objective PSO, namely Adaptive-Grid (AG) and Pareto Entropy (PE) PSO mentioned in section 4. For the three optimisers, the population or swarm sizes are all set as 40, 
Table 5: Free parameters settings.

\begin{tabular}{lll}
\hline Parameters & Lower bound & Upper bound \\
\hline$\gamma_{A}$ & $3^{\circ}$ & $12^{\circ}$ \\
$V_{B}$ & $80 \mathrm{~m} / \mathrm{s}$ & $100 \mathrm{~m} / \mathrm{s}$ \\
$h_{B}$ & $243.84 \mathrm{~m}$ & $457.2 \mathrm{~m}$ \\
$\gamma_{B}$ & $3^{\circ}$ & $12^{\circ}$ \\
$V_{D}$ & $80 \mathrm{~m} / \mathrm{s}$ & $125 \mathrm{~m} / \mathrm{s}$ \\
$N_{1 C D}$ & $70 \%$ & $103 \%$ \\
$x_{C}$ & $-16,000 \mathrm{~m}$ & $-6,000 \mathrm{~m}$ \\
$y_{c}$ & $-4,000 \mathrm{~m}$ & $8,000 \mathrm{~m}$ \\
\hline
\end{tabular}

maximum iterations are set to be 20. The PSO parameters $c_{1}, c_{2}$ and $\omega$ in Table 6 are, respectively, set according to their original suggestions. In multi-objective PSO, the maximum capacity for the global archive is 100 . The special parameters of GA are set according to [52].

Table 6: Features and parameter settings of multi-objective PSO.

\begin{tabular}{lll}
\hline Features & PE & AG \\
\hline Archive strategy & Parallel cell distance and entropy feedback & Adaptive grid \\
gBest selection & Leader group & Adaptive grid \\
pBest selection & pArchive & One pBest+dominance \\
Perturbation & Elitist learning strategy & Rapidly decreasing \\
Parameter setting & Self-adaptation based on $\triangle$ Entropy & $\omega=0.4, c_{1}=c_{2}=1.429$ \\
\hline
\end{tabular}

The preliminary Pareto-optimal solutions obtained by the three optimisers are shown in Figure 5 with ground tracks presented in Figure 6, Figure 7 and Figure 8. From Figure 5 the GA has the largest size of solution set while PE has the least number of solutions. Optimised solutions obtained by AG and GA dominate quite a few of the solutions of PE after the same number of iterations. By comparing solution sets of GA and AG, it is found that both of the optimisers have solutions dominated by the other yet they in combination display a smoother Pareto front with gaps filled by solutions from the other set. Although the ones obtained by GA dominate more solutions obtained by AG, the fact that the AG reaches the extreme values of two objectives and reaches the closest point, namely Solution 3/4 designated by green numbers in Figure 8, demonstrates a better potential of exploration and divergence than GA. To get these solutions, each of the three optimizers executed 800 evaluations to reach the stop condition. Note that for PSO-based algorithms, the calculation of cost functions is not executed if the solution is unfeasible. As a result, for the same total number of evaluations, the computation time of AG and PE are 67.67h and 67.98h respectively, which cut down $5.29 \%$ and $4.86 \%$ of the computational cost, compared with the time spent using NSGA-II.

Five representative solutions are selected from the Pareto-optimal solutions obtained by each optimizer for further analysis: Solution 1 stands for $\min (\mathrm{EPNL})$; Solution 2 represents the $\min \left(\mathrm{CO}_{2}\right)$, and solutions 3 to 5 are the trajectories closest to the utopia point (i.e.(EPNL $\left.\mathrm{EPin}_{\mathrm{m}}, \mathrm{CO}_{2 \mathrm{~min}}\right)$, marked with a pentagram in Figure 5, which are those of minimum preference value and minimum economic cost respectively. They are all indicated with coloured number in Figure 5 


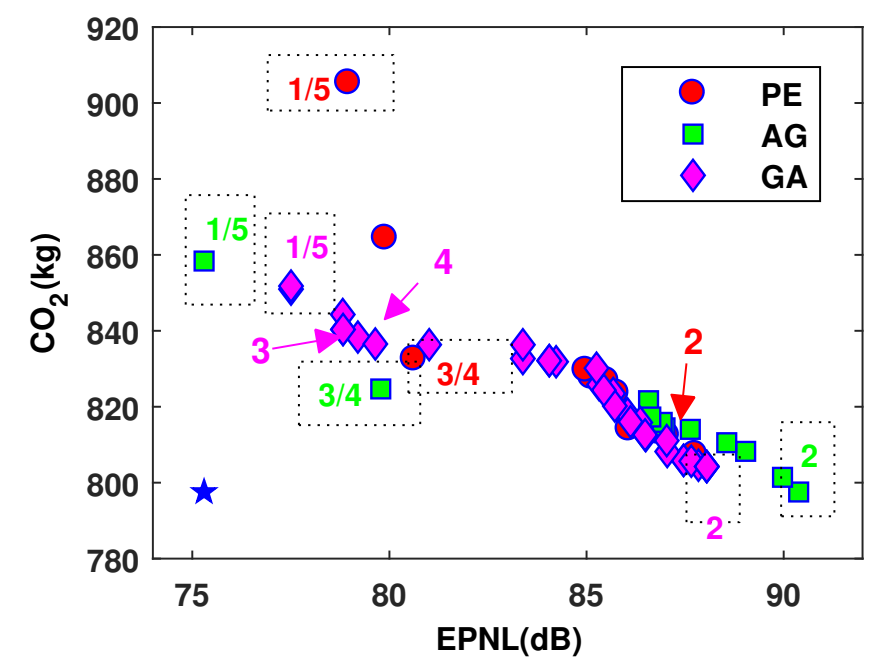

Figure 5: Comparison of optimal solutions obtained by three optimisers.

and are differentiated with line styles in Figures 6-8. Table 7 provides a possible preference classification based on the value range of cost functions actually obtained. Note that $f_{i}^{0}$ are given the values by rounding down the minimum values of the objectives obtained in the optimisation solution set, similarly, $f_{i}^{5}$ are obtained by rounding up the maximum values of the objectives. In order to quantify the increasing undesirability along with the increase of the objective's value and to show the differentiation between each desirability level, the difference between each pair of end points, namely $f_{i}^{k+1}-f_{i}^{k},(k=1,2, \ldots, 4)$, is set to be an arithmetic sequence, which leads to the values displayed in Table 7.

Table 7: Preferences of two objectives.

\begin{tabular}{rrrrrrr}
\hline Objective & $f_{i}^{0}$ & $f_{i}^{1}$ & $f_{i}^{2}$ & $f_{i}^{3}$ & $f_{i}^{4}$ & $f_{i}^{5}$ \\
\hline EPNL $[\mathrm{dB}]$ & 75.00 & 76.07 & 78.20 & 81.40 & 85.67 & 91.00 \\
$\mathrm{CO}_{2}[\mathrm{~kg}]$ & 797.00 & 801.13 & 809.40 & 821.80 & 838.33 & 931.00 \\
\hline
\end{tabular}

From Figure 6 (a) to Figure 8 (a), it can be gleaned that the three optimisers produce a scattered distribution of ground tracks. By analysing the distribution of the horizontal tracks, it can be found that the greater the horizontal distance between the aircraft and the ground receivers, the lower the noise level generated in the NSA. However, this is not always true because the influence that vertical movements put on noise levels also cannot be ignored. In the three sets of the lateral tracks, there are many tracks clustered close to the NSA, with similar even coincident ground tracks, yet very different corresponding optimal objective values. Further analysis indicates that the main difference reflects in their vertical profiles, which illustrates that there is a great optimisation potential in the operations of the vertical plane. More detailed comparison on the representative solutions shown in Figure 6 (b) to Figure 8 (b) is given in Table 8, with the objectives and the results obtained from the posterior selection. 


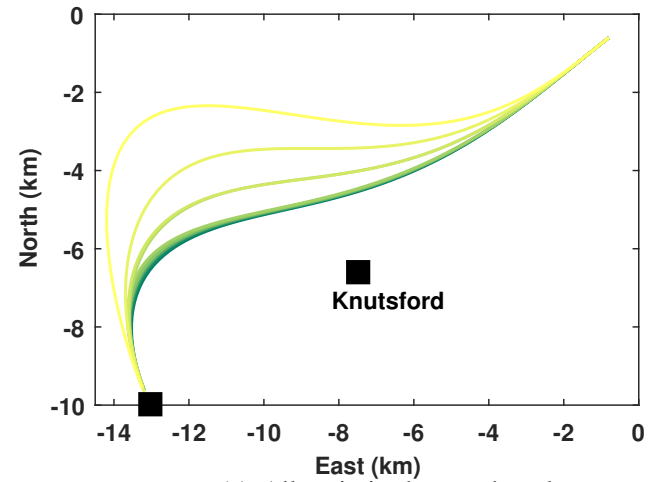

(a) All optimised ground tracks

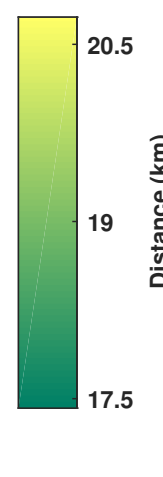

20.5

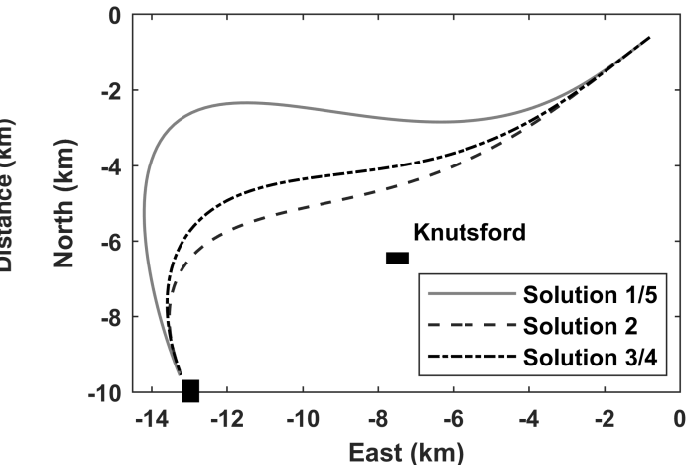

(b) Representative optimised ground tracks.

Figure 6: Optimal ground tracks obtained by PE.

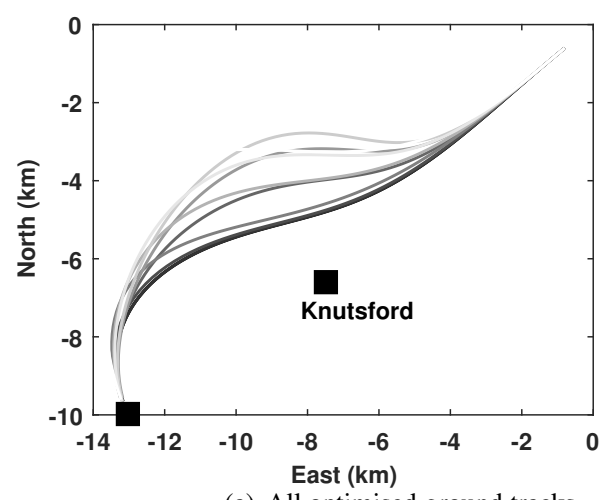

(a) All optimised ground tracks

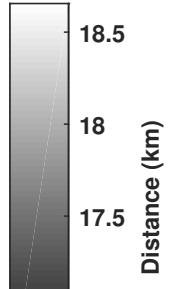

17

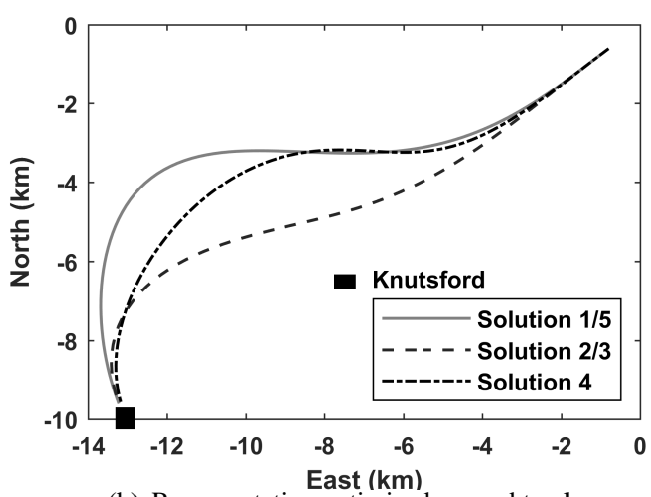

(b) Representative optimised ground tracks.

Figure 7: Optimal ground tracks obtained by AG.

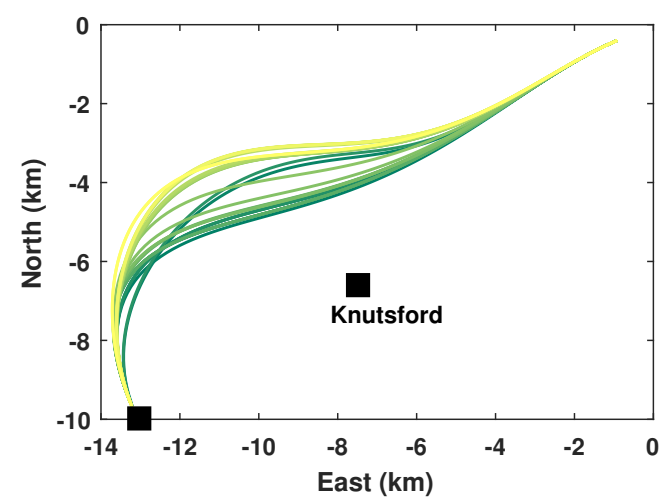

(a) All optimised ground tracks.
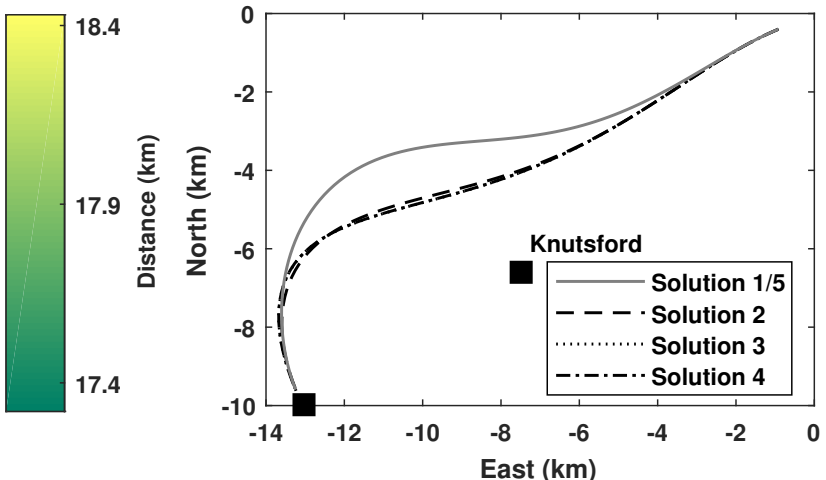

(b) Representative optimised ground tracks.

Figure 8: Optimal ground tracks obtained by GA.

A detailed analysis of noise impact on the ground area around Manchester Airport is conducted by simulating the EPNL produced by the Solution 1 and Solution 3/4 obtained by AG. The simulation scenario is shown in Figure 9 
Table 8: Comparison of objectives of the representative cases.

\begin{tabular}{llllllll}
\hline $\begin{array}{l}\text { Solution } \\
\text { group No. }\end{array}$ & Optimiser & $\begin{array}{l}\mathrm{EPNL} \\
{[\mathrm{dB}]}\end{array}$ & $\begin{array}{l}\mathrm{CO}_{2} \\
{[\mathrm{~kg}]}\end{array}$ & $\begin{array}{l}\mathrm{NO}_{\mathrm{x}} \\
{[\mathrm{kg}]}\end{array}$ & Awakenings & $\mathrm{V}(\mathrm{x})$ & Cost [£] \\
\hline 1 & $\mathrm{PE}$ & 78.85 & 905.41 & 3.66 & 127.93 & 0.3589 & 898.95 \\
1 & $\mathrm{AG}$ & 75.30 & 858.38 & 3.41 & 137.48 & 0.2346 & 918.67 \\
1 & $\mathrm{GA}$ & 77.50 & 850.98 & 3.24 & 136.76 & 0.2413 & 912.25 \\
\hline 2 & $\mathrm{PE}$ & 87.75 & 807.56 & 2.97 & 165.29 & 0.2986 & 1019.02 \\
2 & $\mathrm{AG}$ & 90.38 & 797.54 & 3.78 & 183.27 & 0.3188 & 1119.62 \\
2 & $\mathrm{GA}$ & 88.05 & 804.25 & 3.04 & 162.72 & 0.3015 & 1008.55 \\
\hline 3 & $\mathrm{PE}$ & 80.62 & 832.65 & 3.02 & 138.54 & 0.2237 & 909.57 \\
3 & $\mathrm{AG}$ & 79.78 & 824.69 & 2.97 & 141.97 & 0.1763 & 921.28 \\
3 & $\mathrm{GA}$ & 78.82 & 840.35 & 3.15 & 138.20 & 0.2288 & 913.55 \\
\hline 4 & $\mathrm{PE}$ & 80.62 & 832.65 & 3.02 & 138.54 & 0.2237 & 909.57 \\
4 & $\mathrm{AG}$ & 79.78 & 824.69 & 2.97 & 141.97 & 0.1763 & 921.28 \\
4 & $\mathrm{GA}$ & 79.20 & 838.35 & 3.16 & 139.51 & 0.2216 & 918.98 \\
\hline 5 & $\mathrm{PE}$ & 78.85 & 905.41 & 3.66 & 127.93 & 0.3589 & 898.95 \\
5 & $\mathrm{AG}$ & 75.30 & 858.38 & 3.41 & 137.48 & 0.2346 & 918.67 \\
5 & $\mathrm{GA}$ & 77.50 & 850.98 & 3.24 & 136.76 & 0.2413 & 912.25 \\
\hline
\end{tabular}

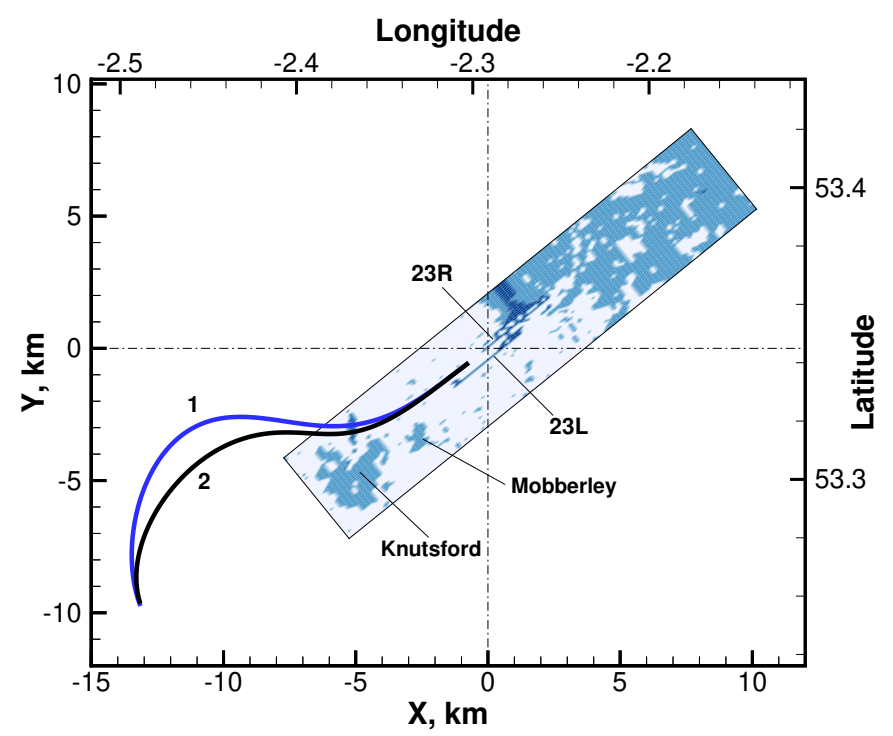

Figure 9: Simulation scenario; colours indicate ground acoustic impedance. Darker shades are built-up areas [53]. Latitude/longitude are degrees. The blue and the black lines indicate the ground tracks of solution 1 and solution 3/4 obtained by AG.

with the blue track indicating Solution 1 and black track indicating Solution 3/4. As is shown in Figure 10, the second trajectory causes much higher noise level on Knutsford, while the first one reduces the EPNL in the NSA with a decrease of more than $5 \mathrm{~dB}$ at the cost of $+3.58 \%$ in $\mathrm{CO}_{2}$ and $+14.81 \%$ in $\mathrm{NO}_{\mathrm{x}}$ emissions.

The vertical profiles of the representative trajectories are presented in Figures 11-13 with altitude and airspeed profiles demonstrated. By comparing trajectories with minimum EPNL in Figures 11-13, we find that in order to eliminate the EPNL in Knutsford, aircraft tend to fly at lower airspeed below 3,000 feet to cut down the noise source 


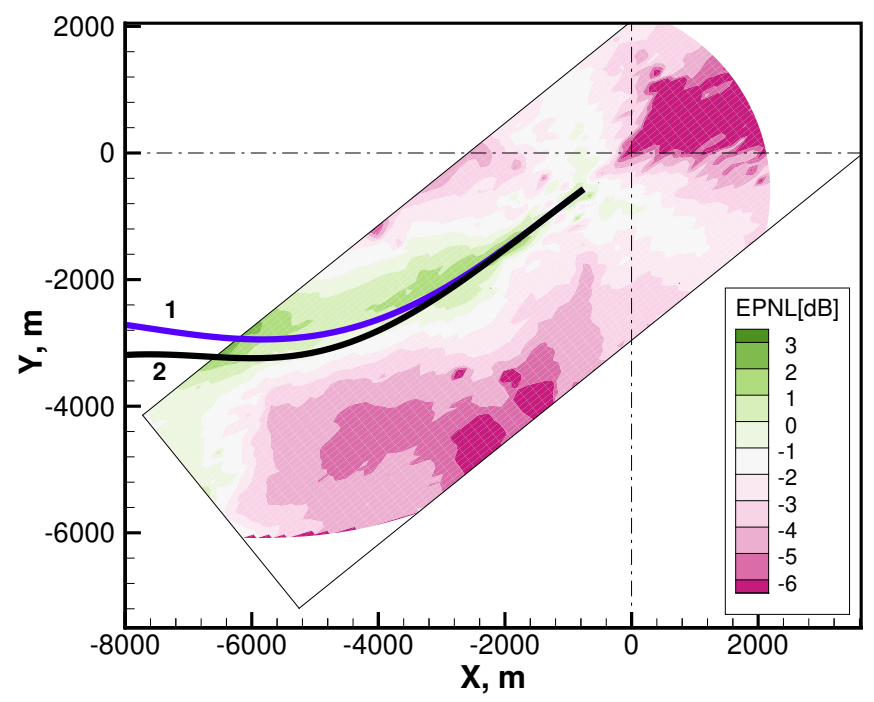

Figure 10: Noise footprint of EPNL difference between two optimised trajectories. The blue and the black lines indicate the ground tracks of Solution 1 and Solution 3/4 obtained by AG.

level. Note that this airspeed should not be too small, otherwise it would take the aircraft longer to climb, leading to a longer exposure time, higher SEL and more awakenings. This can be found in Table 8, where even with a wider detour (black dash-dot line in Figure 7(b)) and much lower speed (black dash-dot line in Figure 12 (b)), the trajectory from AG still awakes more population $(+12.63 \%)$ compared with the one obtained by GA in the same trajectory group 2. At 3,000 feet, if the horizontal distance is far enough from the ground residential community, an acceleration segment with larger acceleration will allow for a faster departure from the receiver without significantly increasing the noise impacts. On the contrary, if the aircraft is close to the ground receiver at the horizontal plane, a quicker level acceleration segment creates more noise than a slower acceleration.

A further comparison is made based on the objectives and the result obtained from posterior selection listed in Table 8. It is noted that all the trajectories with minimum EPNL in each solution set turn out to be optimal based on the monetisation method too, according to Eq. 27. An analysis of the first group of trajectories shows that even for the trajectory with the least awakenings, the resulting economic cost calculated from Eq. 27 still occupies a total cost as high as $62.47 \%$. This shows that it is the high pricing of UCNPP that makes the number of awakenings a decisive factor in the application of the monetisation method. Second, the result shows that the optimal solutions obtained from the minimum preference value tend to be the same as those closest to the utopia point for both PE and AG. It is due to the theoretical difference of these two posterior methods that makes this phenomenon a coincidence, not a conclusion: the preference value function method is highly dependent on the classification of preference levels identified by DM; identification of the closest trajectory from the utopia point is made without the anthropic factor. 


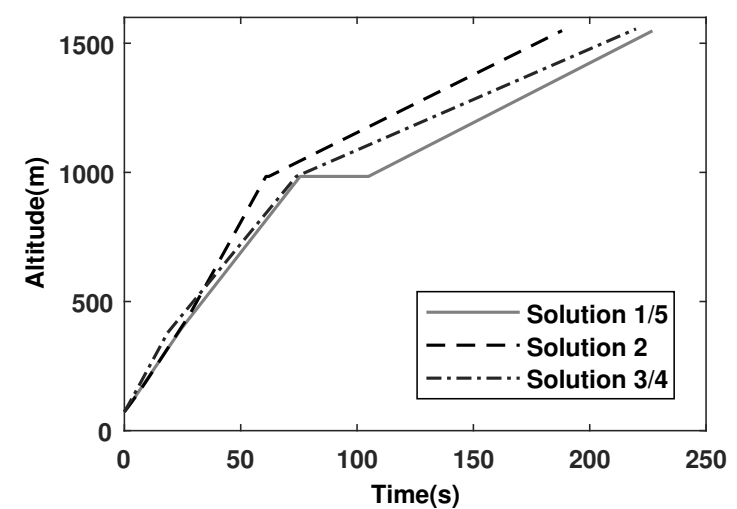

(a) Altitude profile

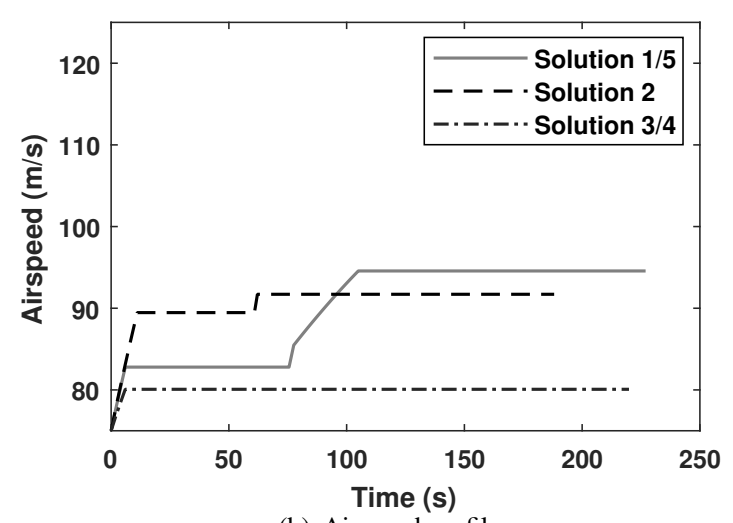

(b) Airspeed profile.

Figure 11: Optimal airspeed and altitude profiles obtained by PE.

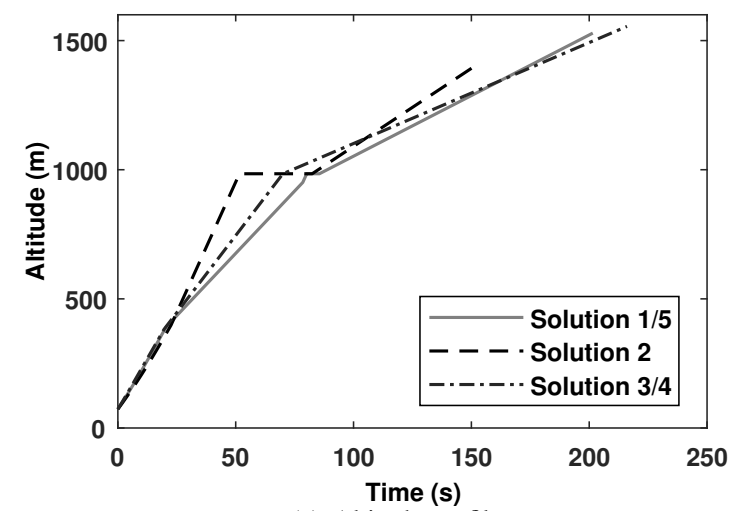

(a) Altitude profile.

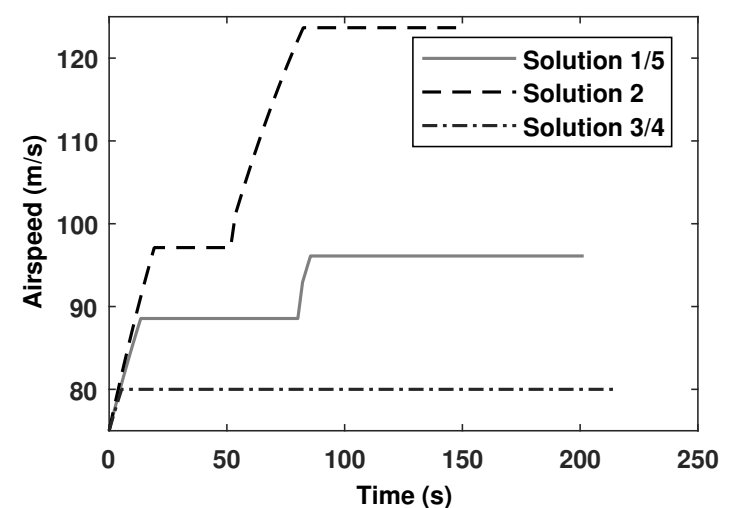

(b) Airspeed profile.

Figure 12: Optimal airspeed and altitude profiles obtained by AG.

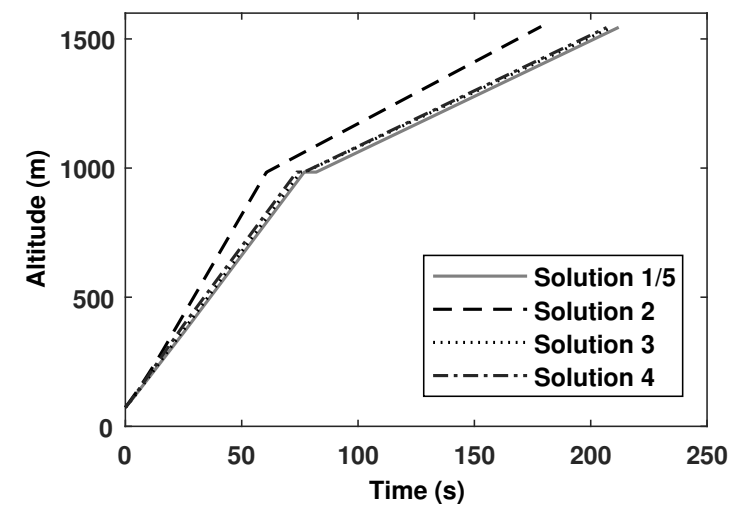

(a) Altitude profile.

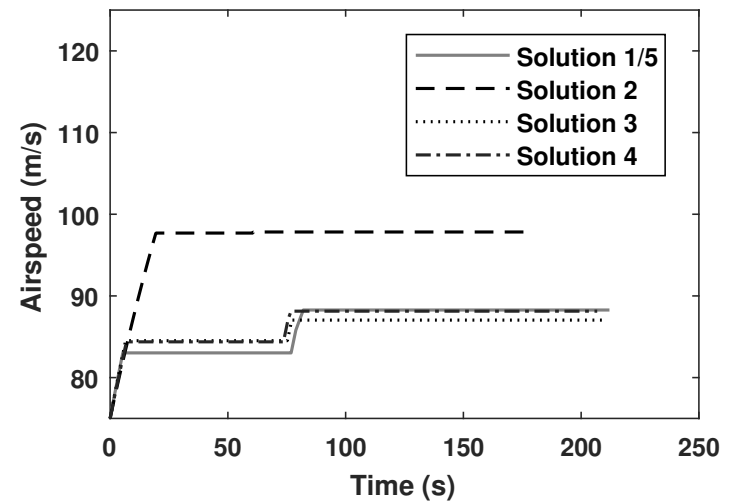

(b) Airspeed profile.

Figure 13: Optimal airspeed and altitude profiles obtained by GA. 
Finally, by comparing the awakenings of each solutions in group 1 (e.g. min(EPNL)) in Table 8 and the correspondent ground tracks, a detour around Knutsford can result in a decrease of awakenings, but not always in EPNL as well. With a posterior evaluation of the Pareto solution sets, the Solution 1/5 of PE is selected by the monetisation method, and Solution 3/4 of AG is selected by the preference function value method.

\section{Conclusions}

This paper presented an optimisation method using non-gradient algorithms for departure trajectory of commercial aircraft, aiming at minimizing multiple environmental impacts on local communities around the airport. A parameterization method is conducted to discretise the dynamics models on both the vertical and lateral planes. Two posterior selection methods are introduced and built to identify the optimal solution of the multi-objective problem. The proposed method is tested in the departure scenario with multiple environmental objectives considered.

In the case shown, a departure trajectory of a commercial aircraft is optimised minimizing multiple objectives. The comparison between three non-gradient methods indicates that multi-disciplinary PSO have inherent advantage in fast convergence yet are not as good as GA in achieving smooth and well distributed Pareto solution set. When solving this kind of multi-objective optimisation problem, it turns out to be wise to apply not only one method. As for the results of trajectory optimisation, it shows that below 3,000 feet, a lower climb target speed for the initial acceleration and constant speed climb is preferred to obtain a quieter departure. Beyond 3,000 feet, a lower airspeed has less impact on noise level, yet it has the potential to reduce the cost of fuel burn and emissions. It is also concluded that a detour is to some extent an effective option to avoid causing high noise level, but only with the flying range limited and with an appropriate airspeed. This is because flying a longer range at a lower airspeed means noise exposure time is increased and more sound energy received, which adds to the risk of awakening. This also has a negative effect on emission cost criterion because there is a direct link between flight duration and a growing amount of jet fuel consumption as well as emissions.

As for the posterior selection method, efforts have been made to monetise the concerned environmental impacts yet it has turned out that the result depends much on the unit pricing. Unlike carbon and nitrogen oxides emissions, monetising impacts of aviation noise can be controversial where there still exists debate around the suitability of effectiveness of the monetisation method established. Compared with monetisation, it has been found that the preference value function method is more applicable with the DM knowledge introduced to guide the decision making process. To overcome the drawback of the monetisation method, there is a need for other authoritative and sophisticated methodologies to monetise aviation noise impact on the basis of flight operations.

\section{Acknowledgments}

The authors gratefully thank the financial support from the China Scholarship Council (File No. 201403170405). 


\section{References}

[1] Civil Aviation Authority, Environmental Research and Consultancy Department, Study on the population trends in the vicinity of ten UK civil airports, Tech. Rep. CAP 1204, Civil Aviation Authority, West Sussex, UK (Jan. 2017).

[2] Sustainable Aviation, The SA noise road-map: A blueprint for managing noise from aviation sources to 2050, Tech. rep., London, UK (2013).

[3] P. P. Team, Survey of Noise Attitudes 2014: Aircraft, Technical Report CAP 1506, Civil Aviation Authority, West Sussex, UK (Feb. 2017).

[4] J. Charles A, Next Generation Air Transportation System, Tech. rep., Integrated Surveilance Study Team (Oct. 2008).

[5] SESAR Joint Undertaking — High performing aviation for Europe, https://www.sesarju.eu/.

[6] Study Group for the Future Air Traffic Systems, Long-term Vision for the Future Air Traffic Systems Changes to Intelligent Air Traffic Systems , Tech. rep., Japan (2010).

[7] O. Fernandes de, On-Board Decoupled Vertical and Lateral Flight Planning for Minimum Emissions and Population Disturbance, in: Proc SAE 2013 AeroTech Congress \& Exhibition, Montréal, Quebec, Canada, 2013. doi:10.4271/2013-01-2299.

[8] X. Prats, V. Puig, J. Quevedo, A multi-objective optimization strategy for designing aircraft noise abatement procedures. Case study at Girona airport, Transportation Research Part D: Transport and Environment 16 (1) (2011) 31-41. doi:10.1016/j.trd.2010.07.007.

[9] H. G. Visser, R. A. Wijnen, Optimization of noise abatement departure trajectories, Journal of Aircraft 38 (4) (2001) $620-627$.

[10] H. Visser, Generic and site-specific criteria in the optimization of noise abatement trajectories, Transportation Research Part D: Transport and Environment 10 (5) (2005) 405-419.

[11] C. R. Hargraves, S. W. Paris, Direct trajectory optimization using nonlinear programming and collocation, Journal of Guidance, Control, and Dynamics 10 (4) (1987) 338-342. doi:10.2514/3.20223.

[12] S. Hartjes, J. Dons, H. Visser, Optimization of Area Navigation Arrival Routes for Cumulative Noise Exposure, Journal of Aircraft 51 (5) (2014) 1432-1438. doi:10.2514/1.C032302.

[13] X. Prats i Menéndez, Contributions to the optimisation of aircraft noise abatement procedures, Degree of Doctor of Philosophy, Universitat Politècnica de Catalunya, Barcelona, Span (2011).

[14] X. Prats, V. Puig, J. Quevedo, F. Nejjari, Multi-objective optimisation for aircraft departure trajectories minimising noise annoyance, Transportation Research Part C: Emerging Technologies 18 (6) (2010) 975-989. doi:10.1016/j.trc.2010.03.001.

[15] S. Khardi, L. Abdallah, Optimization approaches of aircraft flight path reducing noise: Comparison of modeling methods, Applied Acoustics 73 (4) (2012) 291-301. doi:10.1016/j.apacoust.2011.06.012.

[16] R. Torres, J. Chaptal, C. Bès, J.-B. Hiriart-Urruty, Optimal, Environmentally Friendly Departure Procedures for Civil Aircraft, Journal of Aircraft 48 (1) (2011) 11-22. doi:10.2514/1.C031012.

[17] H. Yu, J. A. Mulder, Arrival Trajectory Optimization for Passenger Aircraft using Genetic Algorithms, in: Proc 11th AIAA Aviation Technology, Integration, and Operations (ATIO) Conference, Including the AIA, AIAA, Virginia Beach, VA, USA, 20. doi:10.2514/6.2011-6804.

[18] H. Yu, E. Van Kampen, J. A. Mulder, An Optimization Paradigm for Arrival Trajectories using Trajectory Segmentation and State Parameterization, in: Proc AIAA Guidance, Navigation, and Control Conference, AIAA, San Diego, California, USA, 2016, p. 1872. doi:10.2514/6.2016-1872.

[19] S. Hartjes, H. Visser, Efficient trajectory parameterization for environmental optimization of departure flight paths using a genetic algorithm, Proceedings of the IMechE 231 (6) (2016) 1115-1123. doi:10.1177/0954410016648980.

[20] V. Ho-Huu, S. Hartjes, G. H. Visser, R. Curran, An Efficient Application of the MOEA/D Algorithm for Designing Noise Abatement Departure Trajectories, Aerospace 4 (4). doi:10.3390/aerospace4040054.

[21] A. Filippone, Flight Performance Software FLIGHT, Tech. Rep. AF-AERO-UNIMAN-2014-10, School of Mechanical, Aerospace and Civil Engineering, The University of Manchester, Manchester, UK (Jan. 2015)

[22] T. Hasegawa, T. Tsuchiya, R. Mori, Optimization of Approach Trajectory Considering the Constraints Imposed on Flight Procedure Design, Procedia Engineering 99 (2015) 259-267.

[23] S. Hartjes, H. G. Visser, S. J. Hebly, in: 9th AIAA Aviation Technology, Integration, and Operations Conference (ATIO), Aviation Technology, Integration, and Operations (ATIO) Conferences, American Institute of Aeronautics and Astronautics, 2009. doi:10.2514/6.2009-6953.

[24] D. Delahaye, S. Puechmorel, P. Tsiotras, E. Feron, Mathematical Models for Aircraft Trajectory Design: A Survey, in: Air Traffic Management and Systems: Selected Papers of the 3rd ENRI International Workshop on ATM/CNS (EIWAC2013), Springer Japan, Tokyo, 2014, pp. 205-247.

[25] Z. Song, H. Visser, H. Mingshan, C. Wei, Optimized multi-event simultaneous departure routes for major hub airport, International Journal of Modeling and Optimization 4 (6) (2014) 482.

[26] M. Zhang, A. Filippone, N. Bojdo, Multi-Objective Departure Trajectory Optimisation of Commercial Aircraft on Environmental Impacts, in: The Proceedings of Greener Aviation 2016, Brussels, Belgium, 2016.

[27] A. Filippone, Advanced Aircraft Flight Performance, Cambridge University Press, 2012.

[28] R. C. Eberhart, J. Kennedy, A new optimizer using particle swarm theory, Vol. 1, New York, NY, 1995, pp. 39-43.

[29] V. Kumar, S. Minz, Multi-objective particle swarm optimization: An introduction, SmartCR 4 (5) (2014) 335-353.

[30] K. Parsopoulos, M. Vrahatis, Recent approaches to global optimization problems through Particle Swarm Optimization, Natural Computing 1 (2) (2002) 235-306. doi:10.1023/A:1016568309421

[31] C. A. Coello Coello, A Comprehensive Survey of Evolutionary-Based Multiobjective Optimization Techniques, Knowledge and Information Systems 1 (3) (1999) 269-308. doi:10.1007/BF03325101.

[32] D. Srinivasan, T. H. Seow, Particle swarm inspired evolutionary algorithm (ps-ea) for multiobjective optimization problems, Vol. 4, IEEE, 2003, pp. 2292-2297.

[33] T. Bartz-Beielstein, P. Limbourg, J. Mehnen, K. Schmitt, K. E. Parsopoulos, M. N. Vrahatis, Particle swarm optimizers for Pareto optimization with enhanced archiving techniques, in: Evolutionary Computation, 2003. CEC '03. The 2003 Congress On, Vol. 3, 8, pp. $1780-1787$. doi:10.1109/CEC.2003.1299888.

[34] G. T. Pulido, C. A. Coello Coello, Using Clustering Techniques to Improve the Performance of a Multi-objective Particle Swarm Optimizer, 
in: K. Deb (Ed.), Genetic and Evolutionary Computation - GECCO 2004, Springer Berlin Heidelberg, Berlin, Heidelberg, 2004 , pp. $225-237$. doi:10.1007/978-3-540-24854-5_20.

[35] J. E. Alvarez-Benitez, R. M. Everson, J. E. Fieldsend, A MOPSO Algorithm based exclusively on Pareto Dominance concepts, in: C. A. Coello Coello, A. Hernández Aguirre, E. Zitzler (Eds.), Evolutionary Multi-Criterion Optimization, Springer Berlin Heidelberg, Berlin, Heidelberg, 2005, pp. 459-473. doi:10.1007/978-3-540-31880-4_32.

[36] C. A. C. Coello, G. T. Pulido, M. S. Lechuga, Handling multiple objectives with particle swarm optimization, IEEE Transactions on Evolutionary Computation 8 (3) (2004) 256-279. doi:10.1109/TEVC.2004.826067.

[37] W. Hu, G. G. Yen, Density estimation for selecting leaders and maintaining archive in MOPSO, in: 2013 IEEE Congress on Evolutionary Computation, 2013, pp. 181-188. doi:10.1109/CEC.2013.6557569.

[38] W. Hu, G. G. Yen, X. Zhang, Multiobjective particle swarm optimization based on Pareto entropy, Ruan Jian Xue Bao/Journal of Software 25 (5) (2014) 1025-1050. doi:10.13328/j.cnki.jos.004496.

[39] W. Hu, G. G. Yen, Adaptive multiobjective particle swarm optimization based on parallel cell coordinate system, IEEE Transactions on Evolutionary Computation 19 (1) (2015) 1-18. doi:10.1109/TEVC.2013.2296151.

[40] A. Messac, Physical programming-effective optimization for computational design, AIAA journal 34 (1) (1996) 149-158. doi:https://doi.org/10.2514/3.13035.

[41] J. Sanchis, M. A. Martínez, X. Blasco, Integrated multiobjective optimization and a priori preferences using genetic algorithms, Information Sciences 178 (4) (2008) 931-951. doi:10.1016/j.ins.2007.09.018.

[42] ANSI, Quantities and Procedures for Description and Measurement of Environmental Sound Part 6: Methods for Estimation of Awakenings Associated with Outdoor Noise Events Heard in Homes (Jan. 2008).

[43] World Health Organization, Burden of disease from environmental noise: Quantification of healthy life years lost in Europe, in: Burden of Disease from Environmental Noise: Quantification of Healthy Life Years Lost in Europe, 2011, pp. 126-126.

[44] O. Zaporozhets, V. Tokarev, K. Attenborough, Aircraft Noise: Assessment, Prediction and Control, CRC Press, 2011.

[45] The Centre for Strategy \& Evaluation Services LLP, Evaluation of Directive 2002/49/EC Relating to the Assessment and Management of Environmental Noise Finial Report, Publications Office of the European Union, Brussels, 2016.

[46] Defra, Valuing impacts on air quality: Updates in valuing changes in emissions of Oxides of Nitrogen (NOx) and concentrations of Nitrogen Dioxide (NO2), Tech. rep., Department for Environment, Food and Rural Affairs (Defra) (Sep. 2015).

[47] Department for Business, Energy and Industrial Strategy, Updated Short-term Traded Carbon Values Used for Modelling Purposes, Tech. rep. (Jan. 2018).

[48] Department of Energy and Climate Change, Carbon Valuation in UK Policy Appraisal: A Revised Approach, Tech. rep., Department of Energy and Climate Change (Jul. 2009).

[49] C. Miyoshi, K. J. Mason, The damage cost of carbon dioxide emissions produced by passengers on airport surface access: The case of Manchester Airport, Journal of Transport Geography 28 (2013) 137-143. doi:10.1016/j.jtrangeo.2012.12.003.

[50] W. D. Nordhaus, Revisiting the social cost of carbon, Proceedings of the National Academy of Sciences 114 (7) (2017) $1518-1523$. doi:10.1073/pnas.1609244114.

[51] S. Reis, T. Liska, S. Steinle, E. Carnell, D. Leaver, E. Roberts, M. Vieno, R. Beck, U. Dragosits, UK Gridded Population 2011 based on Census 2011 and Land Cover Map 2015 (2017).

[52] K. Deb, A. Pratap, S. Agarwal, T. Meyarivan, A fast and elitist multiobjective genetic algorithm: NSGA-II, Evolutionary Computation, IEEE Transactions on 6 (2) (2002) 182-197. doi:10.1109/4235.996017.

[53] A. Filippone, A. Harwood, Flyover noise measurements and predictions of commercial airplanes, Journal of Aircraft 53 (2) (2015) $396-405$. doi: $10.2514 /$ C. 033370 . 